\title{
Correction to: Cellular distribution of cadmium in two amaranth (Amaranthus mangostanus L.) cultivars differing in cadmium accumulation
}

\author{
Keyu Chi ${ }^{1,2,3} \cdot$ Rong Zou $^{2,3} \cdot$ Li Wang $^{2,3} \cdot$ Wenmin Huo ${ }^{2,3,4} \cdot$ Hongli Fan $^{2,3}$ (D)
}

Published online: 10 June 2019

(C) Springer-Verlag GmbH Germany, part of Springer Nature 2019

\section{Correction to: Environmental Science and Pollution Research https://doi.org/10.1007/s11356-019-05390-w}

The article Cellular distribution of cadmium in two amaranth (Amaranthus mangostanus L.) cultivars differing in cadmium accumulation, written by Keyu Chi, Rong Zou, Li Wang, Wenmin Huo and Hongli Fan, was originally published electronically on the publisher's internet portal (currently SpringerLink) on 21 May 2019 with open access.
With the author(s)' decision to step back from Open Choice, the copyright of the article changed on June 2019 to CSpringer-Verlag GmbH Germany, part of Springer Nature 2019 and the article is forthwith distributed under the terms of the copyright.

Publisher's note Springer Nature remains neutral with regard to jurisdictional claims in published maps and institutional affiliations.

The online version of the original article can be found at https://doi.org/ 10.1007/s11356-019-05390-w

Hongli Fan

fanhongli@caas.cn

1 Beijing Construction Engineering Group Environmental Remediation Co., Ltd., Beijing 100015, People's Republic of China

2 Institute of Agricultural Resources and Regional Planning, Chinese Academy of Agricultural Sciences, Beijing, People's Republic of China

3 Key Laboratory of Plant Nutrition and Fertilizer, Ministry of Agriculture, Beijing 100081, People's Republic of China

4 School of Land Science and Technology, China University of Geosciences, Beijing 100083, People's Republic of China 